\title{
A case of para-urethral leiomyoma
}

\author{
Anuruddha M Abeygunasekera', LU Gihan ${ }^{2}$, Chamini de Silva ${ }^{2}$ \\ ${ }^{1}$ Urological Surgeon, ${ }^{2}$ Senior House Officer, Urology Unit, Colombo South Teaching Hospital. \\ e-mail address of the corresponding author,Dr.Anuruddha M. Abeygunasekera: amabey@sltnet.lk
}

\section{Case report}

A 68 year-old woman noticed a gradually enlarging lump in her vulva (Figure 1). She was otherwise symptom-free, but the lump continued to increase in size. After eight months she sought treatment. Her urinary stream was good and had no lower urinary tract symptoms or haematuria. There was no vaginal discharge or abdominal pain. Physical examination revealed a spherical lump with a neck arising from the left side of the vulva displacing the urethral meatus to the right (Figure 2).

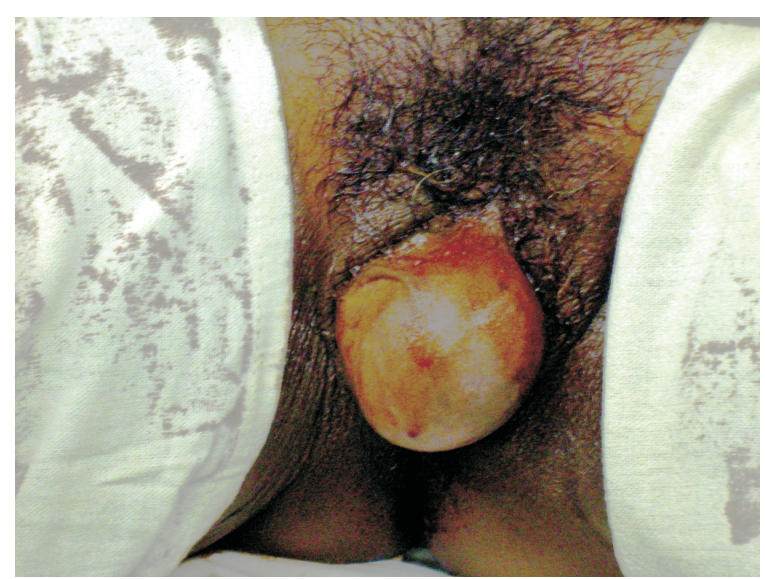

Figure 1 - Shows the vulval lump
It was firm in consistency. The vaginal examination was normal. Abdominal ultrasonography did not reveal any abnormality. Under spinal anaesthesia excision of the lump was done (Figure 3 ). Though the lump was placed very close to the urethra removal was possible without damaging the urethra. The histopathology revealed a para-urethral leiomyoma.

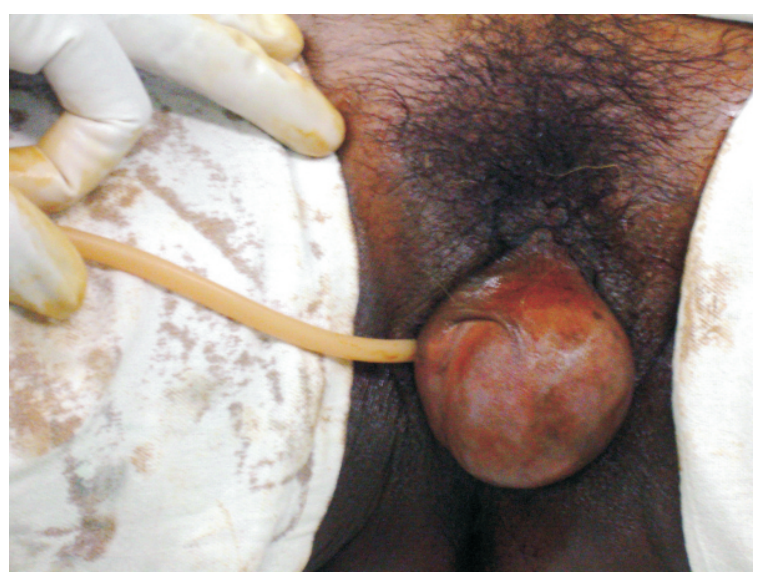

Figure 2 - Shows the displaced urethra with the catheter in situ

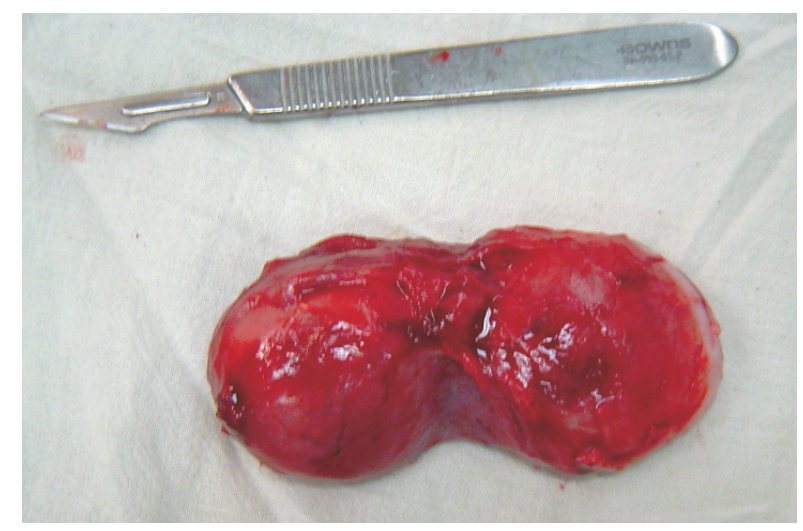

Figure 3 - Shows the excised lump 


\section{Discussion}

Urethral and para-urethral leiomyomas are rare and can occur in both sexes though commoner in females ${ }^{1}$. It is commonly seen in the $35-50$ year age group although this patient was in her late sixties. Usually these patients complain of a palpable mass but the symptomatology may vary. The symptoms are due to the compression of nearby structures and include dysuria, poor urinary stream, dyspareunia and vaginal discharge $e^{2}$. The vulval lump may be mistaken for uterovaginal prolapse, a urethral diverticulum or a periurethral vaginal wall cyst. Proper physical examination helps to exclude a prolapsed uterus. However a precise clinical diagnosis is difficult and the diagnosis is generally based on histopathology. In young men it may be mistaken for other causes of bladder outflow obstruction like urethral stricture disease ${ }^{3}$.

Complete excision of the tumour can be done through a perineal approach in most instances. But large tumours may require a trans-abdominal approach $^{4}$. The histopathological features of urethral or para-urethral leiomyomas are similar to leiomyomas elsewhere. Recurrence or sarcomatous changes are rare.

\section{References}

1. Bai SU, Jung HJ, Leon MJ, Jungda J, Kim SK. Leiomyomas of the female urethra and bladder: a report of five cases and review of the literature. International Urogynaecological Journal of Pelvic Floor Dysfunction 2007: 18; 913-7.

2. Ozel B, Ballard C. Urethral and parapelvic leiomyomas in the female patient. Urogynaecological Journal of Pelvic Floor Dysfunction 2006: 17; 93-5.

3. Costantini E, Cochetti G, Porena M. Vaginal paraurethral mixoid leiomyoma: case report and review of the literature. Urogynaecological Journal of Pelvic Floor Dysfunction 2008: 19; $1183-5$

4. Perera Neville D, Senanayake Lakshman, Vithana V Hasanthi, Fernando Ruchira. An unusual presentation of female urethral leiomyoma. The Ceylon Medical Journal 2005: 50; 31-2. 